\title{
Diurnal cycle of precipitation amount and frequency in Sweden: observation versus model simulation
}

\author{
By JEE-HOON JEONG ${ }^{1 *}$, ALEXANDER WALTHER ${ }^{1}$, GRIGORY NIKULIN ${ }^{2}$, \\ DELIANG CHEN ${ }^{1,} \dagger$ and COLIN JONES ${ }^{2},{ }^{1}$ Department of Earth Sciences, University of Gothenburg, \\ Box 460, SE-405 30 Gothenburg, Sweden; ${ }^{2}$ Rossby Centre, SMHI, SE-601 76 Norrköping, Sweden
}

(Manuscript received 31 July 2010; in final form 26 January 2011)

\begin{abstract}
This study investigated the diurnal cycle of precipitation in Sweden using hourly ground observations for 1996-2008. General characteristics of phase and amplitude for the diurnal cycle of precipitation, both in amount and frequency, were identified. In the warm season (April-September), the 'typical' afternoon (14-16 LST) peaks are dominant over inland Sweden, whereas late night to early morning (04-06 LST) peaks with relatively weak amplitude are discernable in the east coast along the Baltic Sea. The diurnal variation is almost negligible in the cold season (October-March), due to the weak solar radiation at high latitudes. The variations of convective activity forced by solar heating and modulated by geographical characteristics were suggested as primarily factors to invoke the cycles and spatial variation identified. The observed cycle was compared with the cycle simulated by a regional climate model. The model fairly well captures the spatial pattern of the phase of the diurnal cycle. However, the warm season afternoon peak is simulated too early and too uniformly across the stations, associated with too frequent occurrences of convective rainfall events with relatively light intensity. These discrepancies point to the need to improve the convection parametrization and geographic representation of the model.
\end{abstract}

\section{Introduction}

The diurnal variation of precipitation is one of the pronounced natural cycles found in the Earth's climate. Basically arisen from the punctual variation of solar radiation, the associated variations of pressure, wind, temperature and many other climatic factors determine the characteristics of the diurnal cycle of precipitation. In order to identify this cycle, extensive studies have been carried out for various regions in the world through in situ and satellite observations (e.g. Wallace, 1975; Dai, 2001; Dai et al., 2007; and many references therein). A variety of physical mechanisms were suggested to explain its physical mechanisms: wind convergence, terrain uplift, coastal land-sea breeze and tidalvariation of pressure (e.g. Brier and Simpson, 1969; Wallace, 1975; Dai and Deser, 1999; Dai and Wang, 1999). Overall, the afternoon peak caused by convective rainfall in the continental regions versus a nighttime peak caused by relatively light rainfall in regions with maritime climates was a commonly found feature. The detailed regional characteristics and mechanisms of

\footnotetext{
*Corresponding author.

e-mail: jee-hoon.jeong@gvc.gu.se

$\dagger$ Currently on leave.

DOI: $10.1111 / \mathrm{j} .1600-0870.2011 .00517 . x$
}

the diurnal cycle vary greatly depending on location and season (e.g. Yin et al., 2009), and still remain quite uncertain.

Although it is a fundamental cycle in weather and climate, sophisticated climate models-global (GCM), regional (RCM) and even finer scale cloud resolving models-still have large deficiencies in reproducing its exact nature (Guichard et al., 2004; Shin et al., 2007; Lenderink and van Meijgaard, 2008; Samuelsson et al., 2011; Rio et al., 2009). Therefore the realistic simulation of the diurnal cycle is one of the important metrics to evaluate the reliability of a climate model, and an important task in order to improve the performance of weather forecasts and climate simulations.

Difficulties in the examination of the diurnal precipitation cycle mostly arise from the lack of reliable subdaily precipitation observations. Owing to many practical reasons, the observation network of automatic rain gauge sensors has been the most feasible way to collect hourly precipitation data covering a spatial domain of interest. However, the number of data sets with sufficiently long timespan and high spatial density for quantifying the much localized nature of the cycle is rather limited. A possible alternative could be the precipitation estimation from polar-orbiting satellites. Particularly, precipitation data retrieved from the satellite-borne radar of the Tropical Rainfall Measuring Mission (TRMM, Kummerow et al., 1998) have been 
extensively utilized to infer the diurnal cycle of precipitation in the tropics (Sorooshian et al., 2002; Takayabu, 2002; Nesbitt and Zipser, 2003). However, the satellite-derived rainfall data over land are still uncertain, and the spatial coverage for sufficient data acquisition is mostly confined to tropical and subtropical latitudes.

So far, only a few studies have investigated the diurnal variation in Sweden and Northern Europe based on ground-based rain-gauge observations. Andersson (1969) examined the diurnal variation of precipitation in Sweden by utilizing twice per day (daytime and nighttime) precipitation records for 39 stations. Despite of the limitation of the sparse temporal sampling, the afternoon peak distinct in summer and its seasonality were identified. Wern and German (2009) and Dahlström (2006) have studied the duration and intensity of rainfall events in Sweden suggesting its possible connection to the diurnal precipitation cycle. This study also aims at quantifying the general characteristics of the diurnal variation of precipitation in Sweden, but a more extensive analysis was done by taking advantage of data obtained from the well-designed hourly precipitation observation network in Sweden. The general features of the diurnal precipitation cycle — phase and amplitude with geographical and seasonal distinction-were identified from reliable records with sufficient spatial and temporal coverage. Additionally the identified features were compared with those simulated by a highresolution RCM. While such a comparison can help validate climate model simulations (Dai and Trenberth, 2004), the verified climate models are the ultimate tools to understand mechanisms that cause precipitation diurnal cycles (Zhang, 2003; Woolnough et al., 2004).

The paper is organized as follows. Data and methods used are described in Section 2. In Section 3 the observed general features of the diurnal precipitation cycle in Sweden are presented, and compared with the results with the RCM simulation in Section 4. We conclude with a summary and discussion in Section 5.

\section{Data and methods}

\subsection{Hourly precipitation observations}

Hourly precipitation data from 104 stations in Sweden for 1996-2008 were provided by the Swedish Meteorological and Hydrological Institute (SMHI). Figure 1 indicates the locations of the stations with underlying topography. Most of central and southern Sweden consists of plains or gently rolling lowland, whereas there is a mountain range covering most of northern Sweden along the Swedish-Norwegian border. There is a long coastline to the Baltic Sea in the east and south, and to the Kattegat in the southwest. The measurement sites are quite evenly distributed over the country except for the northwestern mountainous region having relatively sparse station density. For the analysis, only stations where missing values occupied less than

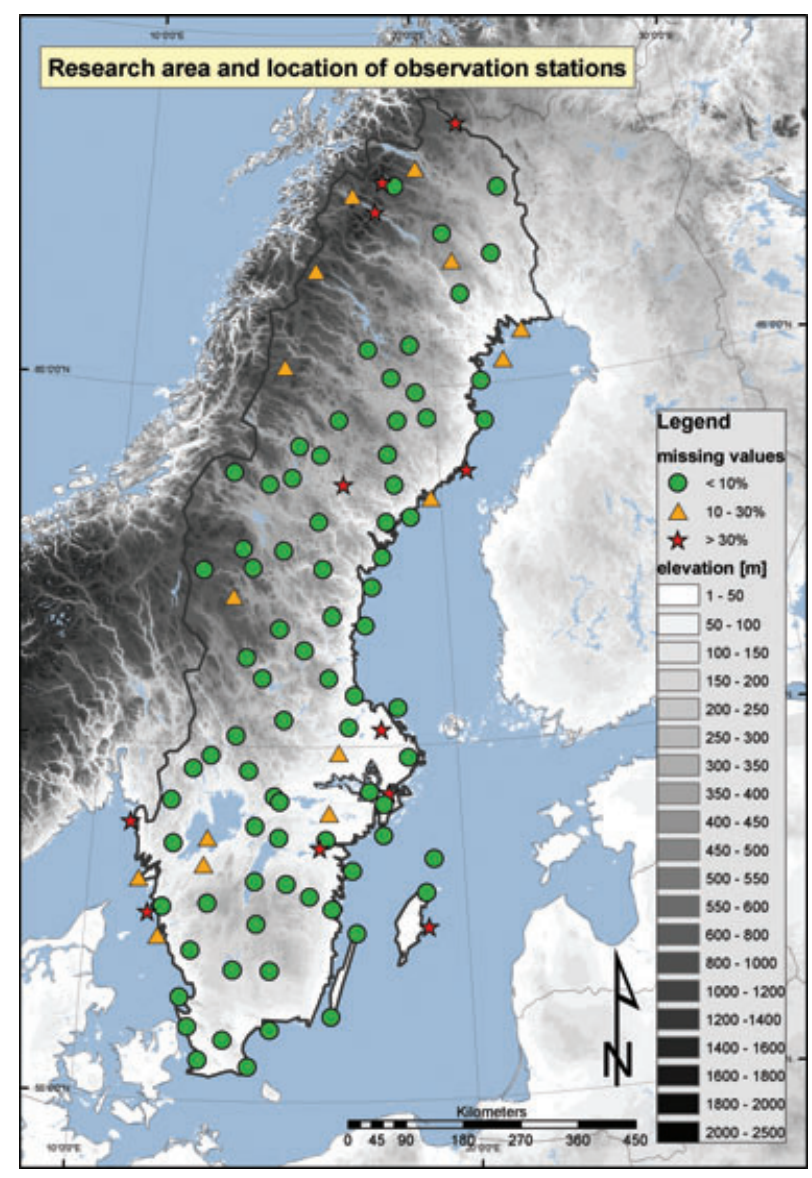

Fig. 1. Geographical location of the observation stations.

$30 \%$ of the total records within the period in focus were selected. This yields data from 93 stations that provide 9.771 .020 hourly measurements in total.

Hourly precipitation measurements at SMHI stations are conducted by GEONOR automatic precipitation gauges (Bakkehoi et al., 1985) with windshield. The resolution of the precipitation intensity given by this instrument is $0.1 \mathrm{~mm} \mathrm{~h}^{-1}$. Following the guidelines of the SMHI data distribution centre, initial quality control was performed in order to treat erroneous negative and unrealistically high precipitation values. The erroneous negative precipitation amounts, obviously arisen from the electronic characteristics of the device, were set to missing records. However, the determination of unrealistically high values is not straightforward, because the threshold for the feasible range of hourly precipitation needs to be determined empirically. Considering the record-high daily total rainfall of $198 \mathrm{~mm}$ measured by an SMHI manual rain gauge on 28 July 1997 in northern Sweden, values higher than $100 \mathrm{~mm} \mathrm{~h}^{-1}$ were set to missing records. In total, 35 cases in the entire record are above $100 \mathrm{~mm} \mathrm{~h}^{-1}$ ( 24 cases with more than $198 \mathrm{~mm} \mathrm{~h}^{-1}$ ) occupying a very small fraction $(0.0004 \%)$. The data set still contains some suspicious values close to $100 \mathrm{~mm} \mathrm{~h}^{-1}$, but we did not discard those values 
in order to conserve the possibility of extreme rainfall, which could happen locally. However, the influence of such extremely high values on the analysis results is thought to be insignificant, as $99.9 \%$ of the precipitation records finally utilized are below $4.7 \mathrm{~mm} \mathrm{~h}^{-1}$. Despite some suspicious values arisen from measurement techniques the database was found to have very high quality which was also well documented by Wern and German (2009).

\subsection{Regional climate model simulation}

We have compared the diurnal cycle of precipitation estimated from the observation data with that simulated by a highresolution regional climate model. We used a long-term simulation of the Rossby Centre Atmospheric Model version 3 (RCA3) driven by the ERA40 re-analysis data set (Uppala et al., 2005). Simulation data for the same period as covered by the observations were utilized. The model domain of the simulation covers most of Europe using a rotated latitude-longitude coordinate system; the latitude range is about $26-72^{\circ} \mathrm{N}$, and the corresponding longitude range is about $4^{\circ} \mathrm{W}-34^{\circ} \mathrm{E}$ and $33^{\circ} \mathrm{W}-57^{\circ} \mathrm{E}$ at the southern and northern boundary, respectively. The horizontal resolution is $50 \mathrm{~km} \times 50 \mathrm{~km}$ approximately (about $0.44^{\circ}$ spacing), and the atmospheric layers are discretized by 24 unequally spaced hybrid terrain-following levels.

RCA3 is known to be one of the best models in simulating weather and climate in Sweden and Scandinavia (Kjellström et al., 2005) and has been utilized in a wide range of climate impact studies (Jones et al., 2011). Initially developed based upon the numerical weather prediction model HIRLAM (Undén et al., 2002), RCA3 builds on the previous version RCA2 (Jones et al., 2004) with significant updates in the land surface scheme and atmospheric parametrizations (Samuelsson et al., 2011). Physical parametrizations of RCA3 include large-scale clouds and microphysics (Rasch and Kristjansson, 1998), convection (Kain and Fritsch, 1993), turbulence (Cuxart et al., 2000) and radiation (Savijärvi, 1990; Sass et al., 1994), and land surface processes with a tiled surface representation (Samuelsson et al., 2006). More details are described in Samuelsson et al. (2008).

\subsection{Estimating the diurnal cycle}

In order to examine the general characteristics of the diurnal cycle of precipitation, first, a long-term average of the hourly precipitation amount $\left(\overline{\mathbf{P}}_{\mathbf{a}}\right)$ and precipitation occurrence frequency $\left(\overline{\mathbf{P}}_{\mathbf{f}}\right)$ at each station for the entire analysis period were calculated from the raw data.

The $\overline{\mathbf{P}}_{\mathbf{a}}$ and $\overline{\mathbf{P}}_{\mathbf{f}}$ are defined as;

$$
\begin{aligned}
\overline{\mathbf{P}}_{\mathbf{a}}(\mathbf{h}) & =\frac{\sum_{\mathbf{d}=\mathbf{1}}^{\mathbf{N}} \mathbf{P}(h, d)}{\mathbf{N}}, \\
\overline{\mathbf{P}}_{\mathbf{f}}(\mathbf{h}) & =\frac{\sum_{\mathbf{d}=\mathbf{1}}^{\mathbf{N}} \mathbf{O}(h, d)}{\mathbf{N}},
\end{aligned}
$$

$\mathbf{O}(h, d)=\left\{\begin{array}{ll}\mathbf{1} & \mathbf{P}(h, d) \geq \mathbf{0 . 1} \mathrm{mm} \mathrm{h}^{-1} \\ \mathbf{0} & \mathbf{P}(h, d)<\mathbf{0 . 1} \mathrm{mm} \mathrm{h}^{-1}\end{array}\right.$,

where $h$ and $d$ are the chosen hour (i.e. 1-24) and day (among days for the entire analysis period) and $N$ is the total number of days. $\mathbf{P}(h, d)$ is the precipitation at a given $h$ and $d$, that is, an hourly accumulated amount before a designated hour $(h)$ both for observation and model. $\mathbf{O}(h, d)$ is a rainfall occurrence counter. The threshold for the precipitation rate of $0.1 \mathrm{~mm} \mathrm{~h}^{-1}$ was used under the specification of the GEONOR sensor.

In order to determine the peak time (phase) and amplitude of the diurnal cycle, smoothed $\overline{\mathbf{P}}_{\mathbf{a}}$ and $\overline{\mathbf{P}}_{\mathbf{f}}$ at each station were calculated by using the harmonic analysis technique (Angelis and McGregor, 2004; Wilks, 2006). A modelled diurnal variation of a chosen station $(\tilde{\mathbf{P}})$ at hour $h$ can be represented by the summation of sinusoidal harmonics as

$\tilde{\mathrm{P}}(h)=\overline{\overline{\mathbf{P}}}+\sum_{k} \mathbf{C}_{k} \cos \left(\frac{2 \pi k h}{24}-\theta_{k}\right)+$ residual,

where $\overline{\overline{\mathbf{P}}}$ is the 24 -h mean of $\overline{\mathbf{P}}, k$ is the harmonic number (i.e. 1 for the 24-h cycle), and $\mathbf{C}_{k}$ and $\theta_{k}$ are the amplitude and the phase of the given $k$-th harmonic. More details of the mathematical representations are in Wilks (2006) and Yin et al. (2009). In this study, the summation of the first (24-h frequency; $k=$ 1) and second (12-h frequency; $k=2$ ) part of the harmonics was defined as mean (smoothed) diurnal cycle. The amplitude of this smoothed diurnal cycle was determined as half the difference between maximum and minimum value within the average 24-h cycle, and the peak timing as the time when the maximum value is found. Those calculations were performed for the warm season (April-September) and cold season (October-March) separately considering the seasonality of precipitation characteristics.

Figure 2 shows an example of the mean diurnal cycle estimated at Blomskog (59.22N/12.08E) in southwestern Sweden. The diurnal cycle modelled by the first and second harmonics (bold lines) well represents the amplitude and peak phase found in the raw data. The general characteristics both for amount and frequency are clearly illustrated; for example, in summer an afternoon peak is clearly found around 15 LST both for precipitation amount and for occurrence frequency. The peak for winter is much weaker and occurs earlier in the morning hours.

Table 1 shows the 'goodness of fit' of the modelled diurnal cycle with respect to the simple mean diurnal cycle for the warm and cold season averaged over all 93 stations. In general, the harmonic model fits better for the warm season and when it comes to precipitation frequency. For the cold season the average goodness-of-fit is considerably lower and the variability of $R^{2}$ among the stations is higher. 
Fig. 2. Average diurnal cycle of observed precipitation at Blomskog station (indicated as red square in the right figure). Blue, solid lines: precipitation amount; dashed lines: frequency of precipitation. Thick line indicates the summation of the first two harmonics (diurnal and semidiurnal) of the raw diurnal cycle, thin line. The variance of the raw diurnal cycle explained by the harmonics is indicated in each panel (blue: amount, black: frequency).
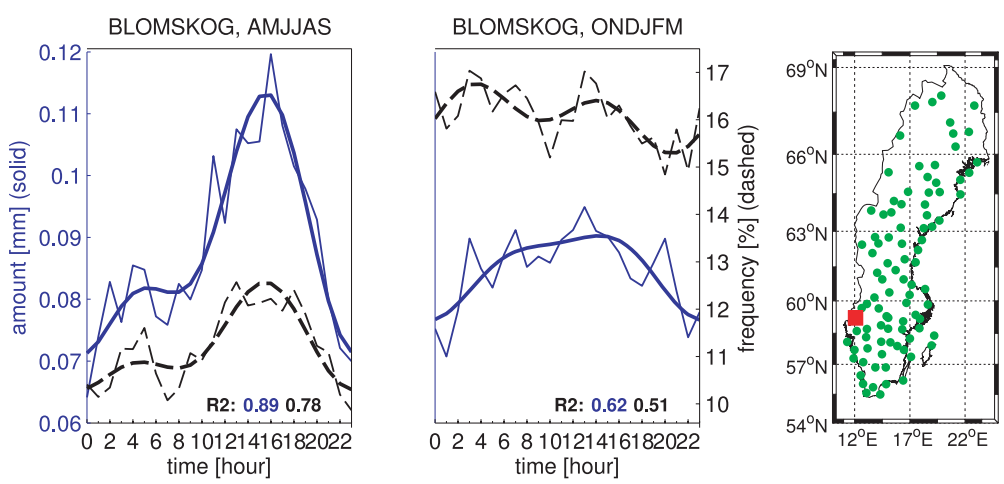

Table 1. Explained variance $\left(R^{2}\right)$ of the mean diurnal cycle of amount and occurrence frequency of precipitation by the modelled diurnal cycle averaged for all 93 stations

\begin{tabular}{|c|c|c|c|c|}
\hline \multirow[b]{2}{*}{$R^{2}$} & \multicolumn{2}{|c|}{$\begin{array}{c}24 \mathrm{~h}+12 \mathrm{~h} \\
\text { (first and second } \\
\text { harmonic) }\end{array}$} & \multicolumn{2}{|c|}{$24 \mathrm{~h}$ (first harmonic) } \\
\hline & Amount & Frequency & Amount & Frequency \\
\hline Warm season & 0.59 & 0.72 & 0.41 & 0.49 \\
\hline Cold season & 0.46 & 0.50 & 0.32 & 0.37 \\
\hline
\end{tabular}

\section{Spatial patterns in peak timing and amplitude in observed diurnal variations}

Figure 3 shows the overall characteristics of the diurnal cycle found in Sweden. Peak time and amplitude of the precipitation amount and frequency are represented for warm (April-September) and cold (October-March) season. The peak time as well as the amplitude of the diurnal cycle exhibit geographical characteristics with distinct seasonality. In the warm season, the inland afternoon peak and the east-coast early morning peak are salient. The majority of inland stations show a clear afternoon maximum of precipitation amount and frequency, mostly pointing at 15-18 LST. Intuitively, it is inferred that the afternoon peak is associated with the daytime variation of incoming solar radiation accumulated to trigger convective activity. Along the eastern coastal line adjacent to the Baltic Sea, on the contrary, clear early morning/morning peaks, but with relatively weaker amplitude, are found at 04-07 LST. This morning peak may reflect local climate characteristics along the Baltic Sea shore, and is reminiscent of the characteristic of oceanic deep convection in the tropics suggested by Yang and Slingo (2011). The land-sea thermal contrast and low-level circulation driven by the contrast may cause this distinct feature. The radiative cooling of the land surface reaches its maximum just before the sunrise, so sufficiently cooled air over inland nearby relatively warmer and moist air over the sea may induce instability in the lower-atmosphere. Also the nighttime development of deep convection over the relatively warmer Baltic Sea may directly affect the early morning peak in the coastal regions. However, the prevailing westerly winds may confine this effect along the narrow coastal region where the different air masses can interact directly. During the daytime, on the contrary, relatively cooler air temperature affected by adjacent maritime air may stabilize the lower troposphere in the coastal regions, which suppresses the chance of convective rainfall occurrence during daytime. The cold season pattern is characterized by an overall morning peak and an afternoon peak in central eastern Sweden. However, the amplitude is very modest except relatively frequent occurrence of precipitation in the northwestern mountainous region. As most of Sweden is located at high latitudes, just to the south of the Arctic Circle, the darker season with very little amount of incoming solar radiation starts early from mid-fall, and convective instability associated with the diurnal variation of surface radiative energy seems to be almost vanished in winter. Andersson (1969) suggested the existence of daytime precipitation peak in the northern mountains in Sweden in winter, but it was not detectable in our records.

Considering the identified spatial pattern of the warm season diurnal cycle and geography, we divided Sweden into three representative regions: two inland areas-the northern mountains (north of $60^{\circ} \mathrm{N}$ ) and the southern plains (south of $60^{\circ} \mathrm{N}$ ) - and the eastern coast (within $20 \mathrm{~km}$ from the shore, east of $15^{\circ} \mathrm{E}$ ). Figure 4 represents the averaged diurnal cycles for these three regions in the warm season. The most distinct diurnal cycle is found in the southern plains. Both the amount and frequency represent a clear afternoon peak around 15-16 LST, and their amplitudes are largest in the three regions. Precipitation in the northern mountains also shows an afternoon peak of similar timing, but of weaker amplitude. The mean precipitation amount is slightly lower than that in the southern plains, whereas the mean frequency is considerably higher (maximum about $12 \%$ at around 16 LST). Orographical lifting seems to induce the frequent occurrence of rainfall, but probably with slightly smaller precipitation intensity compared to the southern inland region. Contrasting to both inland regions, an early morning peak (04-06 LST) is found in the east coast, but both the precipitation frequency and amount are considerably lower and smaller. 

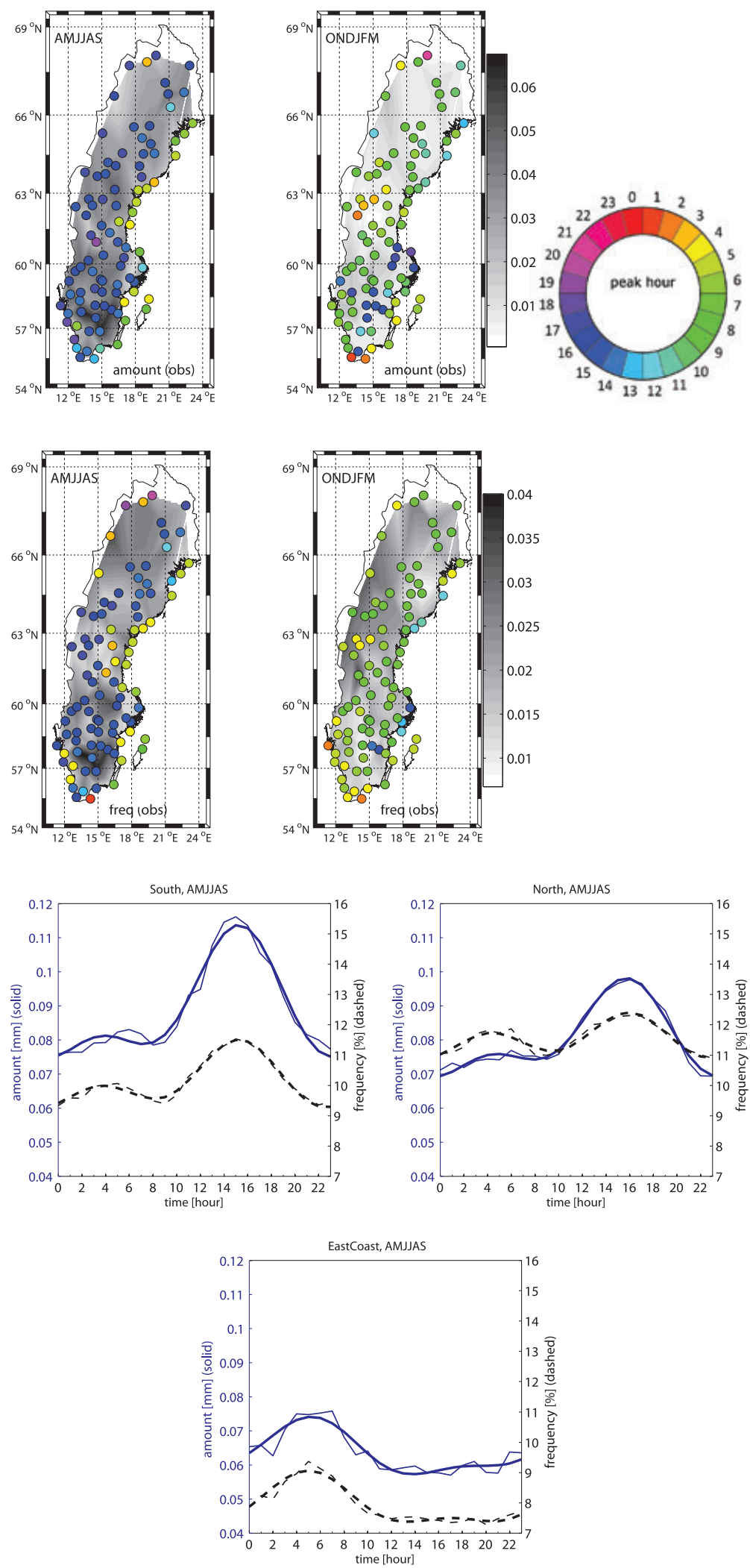

Fig. 4. Average warm season

(April-September) diurnal cycle of observed precipitation amount (blue, solid line) and frequency (black, dashed line) for three representative regions: southern plains (left-hand side), northern mountains (centre) and eastern coast (right-hand side). Thin and thick lines indicate the averages from raw data and modelled (summation of first and second harmonic) diurnal cycle, respectively. 
Considering the peak timing and geographical location, it can be inferred that the afternoon and early morning peak are contributed by precipitation of different type. Although this dependency to the precipitation types on the diurnal cycle could not be directly examined by our data set; the results from Dai (2001) suggest that the inland afternoon peak is mostly contributed by showery precipitation, while the early morning peak in the eastern coast rather matches with the peak of drizzle type of precipitation (see their figs 2 and 4).

The results shown in Figs 3 and 4 clearly represent the distinction of the diurnal cycle with geographical features and seasonality, and the diurnal variation of convective rainfall occurrence is suggested as the main cause. The suggested role of convective precipitation is further investigated by examining the relative contributions of precipitation events with different intensities to the diurnal cycle. Again focusing on the warm season, the spatial distributions of the average precipitation frequency for the four 6-h periods during the day $(0-6,6-12,12-18$ and
18-24 LST) conditioned by different precipitation intensities are shown in Fig. 5. Precipitation intensity larger than $1.1 \mathrm{~mm} \mathrm{~h}^{-1}$ and $3.6 \mathrm{~mm} \mathrm{~h}^{-1}$ is chosen as the threshold for conditioning the 'moderate' and 'heavy' rainfall, respectively. The two thresholds are corresponding to the 75th and 98th percentiles among records with precipitation of more than $0.1 \mathrm{~mm} \mathrm{~h}^{-1}$ intensity from the entire stations for the whole analysis period. Perhaps, precipitation event more than $3.6 \mathrm{~mm} \mathrm{~h}^{-1}$ intensity may not stand for really 'heavy' convective precipitation intensity associated with tropical convections, but seems to be reasonable to say relatively 'heavy' events in such high-latitude climate. Overall, heavier precipitation seems to represent a more distinctive diurnal cycle; the afternoon peak in the southern plains and northern mountains are more distinct in the moderate and heavy precipitation case. Considering relatively higher precipitation intensity for the convective rainfall, this implies that the intense convective activity associated with the diurnal variation of available surface energy considerably contributes to the
Fig. 5. The average frequency of observed precipitation for 6-h periods during the day for the warm season. First row all rain events $\left(\geq 0.1 \mathrm{~mm} \mathrm{~d}^{-1}\right)$, second row rainfall events $>1.1 \mathrm{~mm} \mathrm{~h}^{-1}$ (>98th percentile), third row rainfall events $>6 \mathrm{~mm} \mathrm{~h}^{-1}$ (>99.9th percentile) included. The 98 th and 99.9 th percentiles are based on the whole precipitation records observed over all the 93 stations.
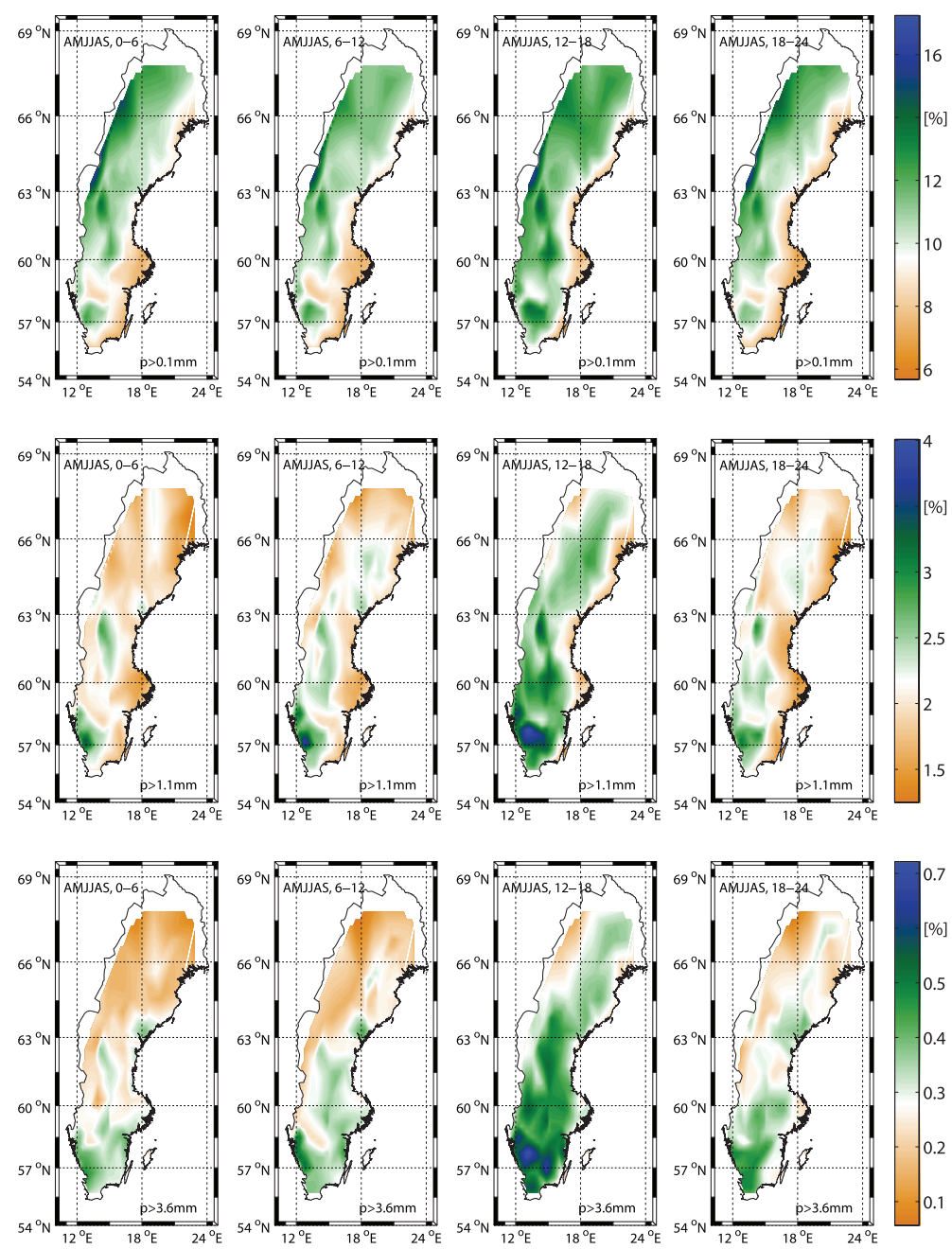
diurnal cycle identified. In the east coast, however, the contribution of moderate and heavy precipitation on the morning peak is not clearly discernable. Thus, the morning peak seems to be not so much contributed by intense convective precipitation events, but the shallow convective instability in the lower troposphere may be mostly responsible for it.

\section{Simulated diurnal cycle by the regional climate model (RCA3)}

We compared the diurnal precipitation cycle identified from observation records with that simulated by the RCA3. To preserve the much localized characteristics of precipitation events, the simulated precipitation data were taken from grid points closest to the 93 observational stations without any spatial interpolation process. The peak time and amplitude were estimated and presented by the same method as for the observation data, and the results are shown in Fig. 6. Overall, the RCA3 model has great difficulties to simulate the exact timing of maximum peaks although it looks like being able to capture some of the pronounced patterns of the diurnal cycle observed: inland-afternoon versus the coastal-morning peak in the warm season and overall early morning peaks in the cold season. First of all, in the warm sea- son, the diurnal cycle of precipitation amount in RCA3 exhibits too early peak timing of the diurnal cycle; over the southern plains and northern mountains, the peaks are almost uniformly pointing at 1200-1330 LST, which is almost $6 \mathrm{~h}$ earlier than the observed timing in many locations. The early morning peaks along the east coast during the warm season are not as well defined as observed, and there are some spurious afternoon peaks. Second, the amplitude of diurnal precipitation cycle in RCA3 is much greater compared to the observed one in the warm season (note that the range of scale bar in Fig. 6 is twice of that in Fig. 3) but that in the cold season is almost negligible and much weaker than observed.

The relative contribution of moderate and heavy precipitation to the diurnal cycle of precipitation in RCA3 was examined in Fig. 7. It is found that those discrepancies are tightly associated with the model's intrinsic deficiency in simulating a realistic distribution of the precipitation intensity. In general, compared to observations, the RCA3 model tends to produce too frequent precipitation of relatively light intensity, which mostly accounts for the diurnal rainfall cycle identified. The precipitation pattern including all events (i.e. intensity $\geq 0.1 \mathrm{~mm} \mathrm{~h}^{-1}$ ) shows a maximum frequency peak in the afternoon over the southern plains, but the value seems to be unrealistically high, more than $25 \%$ for
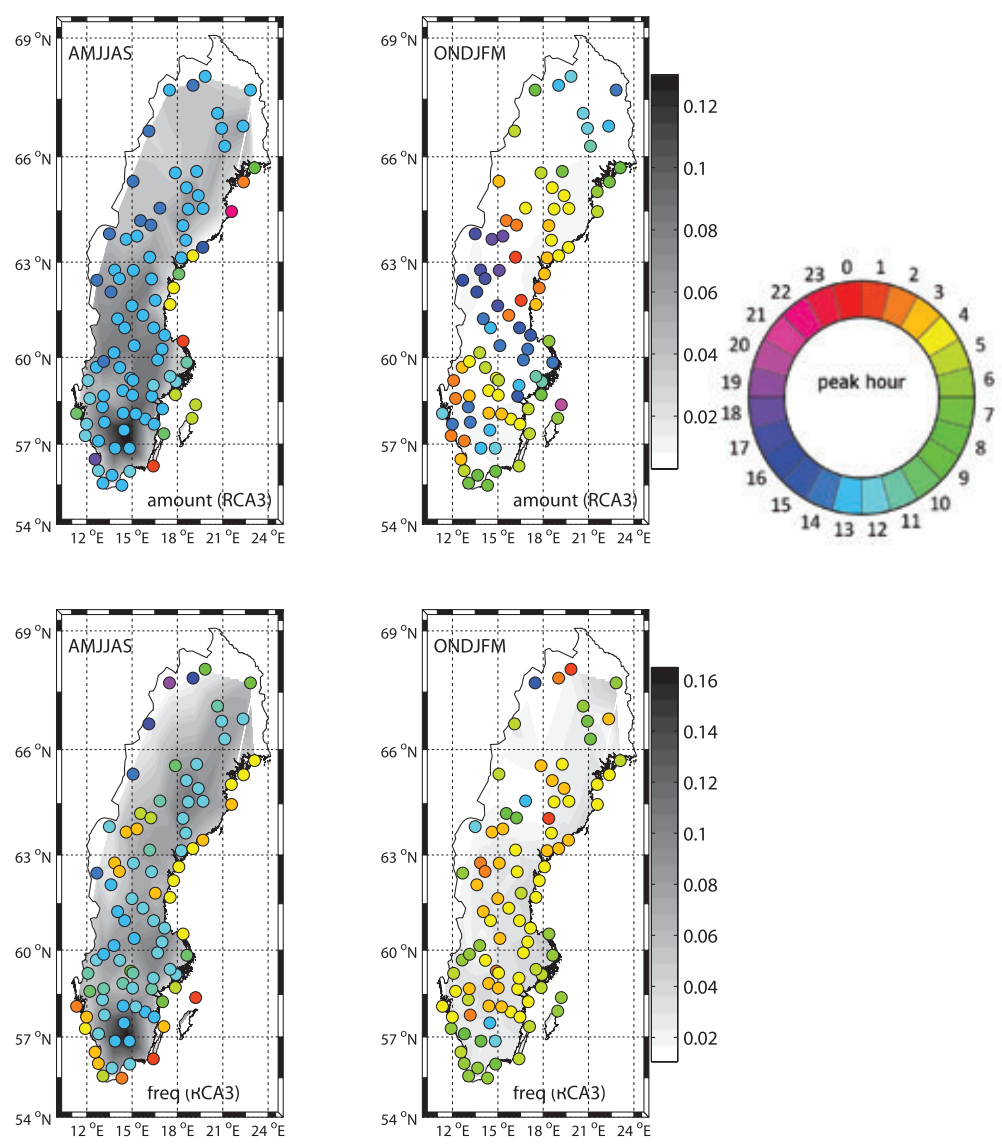

Fig. 6. The same as Fig. 3, but results from RCA3 simulation. 
Fig. 7. The same as Fig. 5, but precipitation from RCA3 simulation
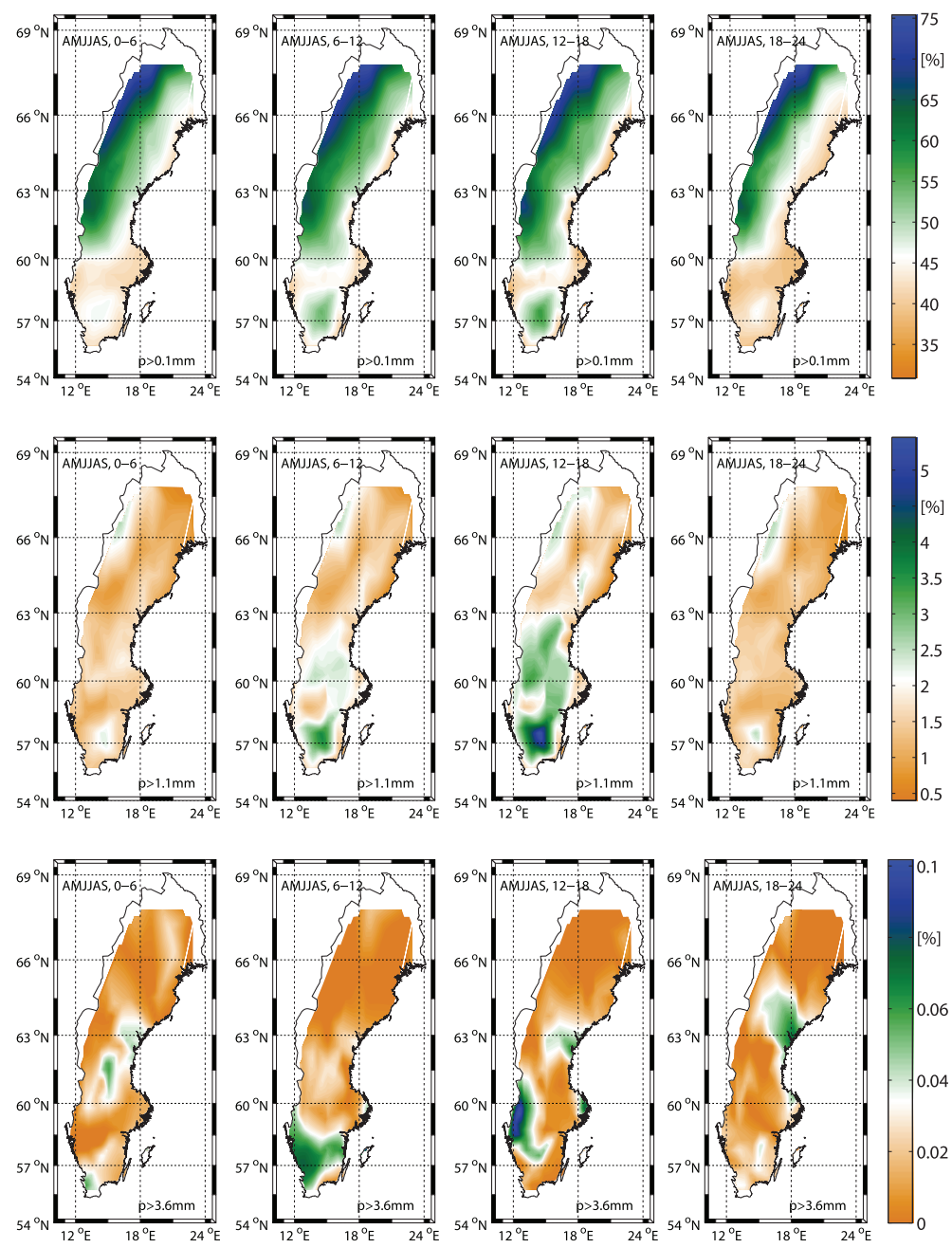

most parts of Sweden. Some afternoon peaks can be seen for the moderate precipitation in southern plains, but the occurrence of precipitation frequency and diurnal variation is almost vanished for heavy precipitation. This discrepancy of the model is more clearly seen in Fig. 8 which compares the probability distribution function of precipitation intensity estimated from observations and RCA3 simulation. Overall, compared to observations, the model simulates too frequent precipitation events of relatively light intensity, less than about $1.6 \mathrm{~mm} \mathrm{~h}^{-1}$. As expected from Fig. 7, this discrepancy is most distinct in the northern mountains. These seem to be originated from a well-known discrepancy found in many other existing climate models. It has been suggested that, due to too sensitive initiation of convective activity in convective parametrization, too frequent convective rainfall with relatively weak intensity leads to early peaks with high amplitude, but prevents the sufficient accumulation of available energy to invoke very strong convective rainfall with intense precipitation (e.g. Shin et al., 2007; Lee et al., 2008; Rio et al., 2009). Also the too frequent topographical precipitation over the mountains is commonly found in many models (Lee et al., 2007).

\section{Summary and discussion}

The general characteristics of the diurnal cycle of precipitation over Sweden were identified by using hourly precipitation data from 93 meteorological stations for the period of 1996-2008. In the warm season, April-September, clear afternoon peaks are found in southern plains and northern mountains while the early morning peak prevails along the eastern coastline. The afternoon peak is clearer for heavier precipitation, so it is suggested that the variation of convective rainfall with strong precipitation intensity may primarily account for the inland afternoon peak. Along the eastern coast, the relatively cooler surface temperature nearby the sea in the early morning seems to produce frequent rainfall events. In the cold season, October-March, the amplitude of the diurnal cycle is very modest as there is only very little incoming solar radiation. 

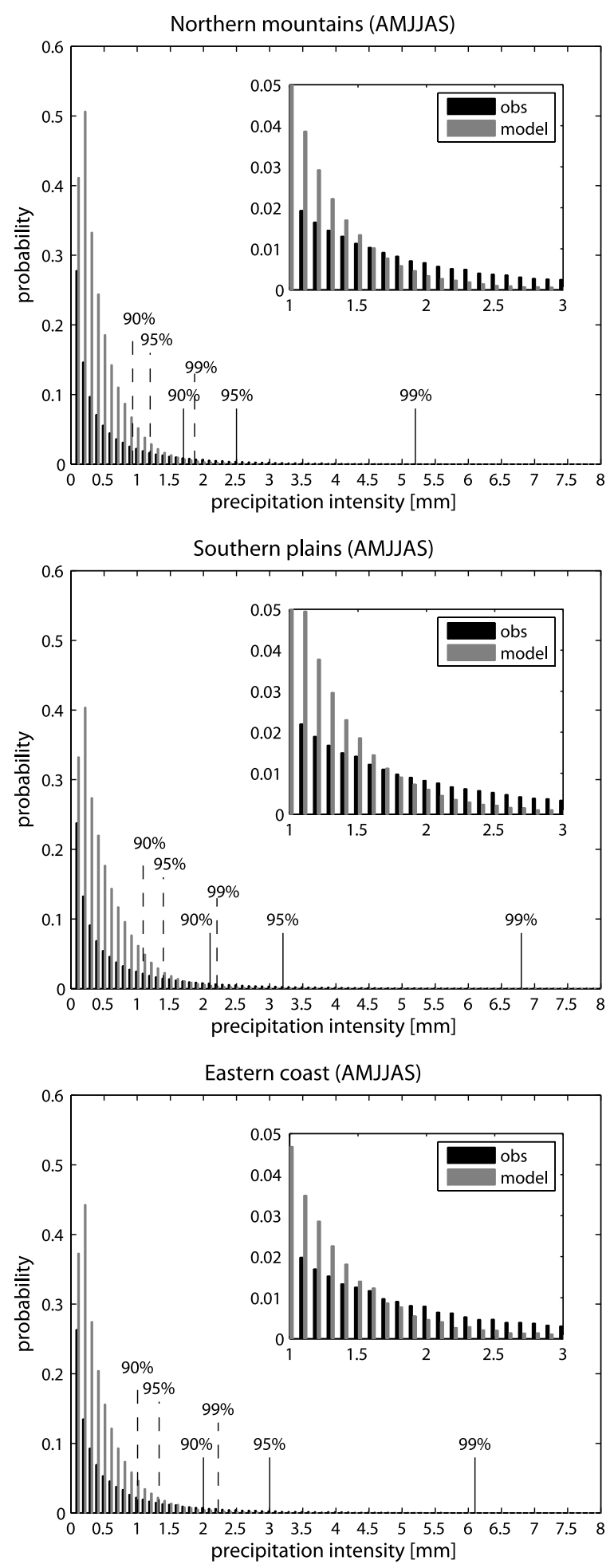

Fig. 8. Probability density of precipitation intensity over the three representative regions: northern mountains (upper panel), southern plains (middle panel) and Eastern coast (bottom panel). Inner boxes highlight the probability of precipitation intensity from $0.1-1 \mathrm{~mm} \mathrm{~h}^{-1}$. The 90th, 95th and 99th percentiles are marked for the observations (solid vertical lines) and the RCA3 simulation (dashed vertical lines).
The identified diurnal variation of precipitation was compared with the RCA3 model simulation. Overall, the model captures the afternoon peak in the inland versus early morning peak in the eastern coast. However, a critical deficiency is the too early timing of the afternoon peak, which seems to be associated with too sensitive initiation of convective activities and too frequent occurrence of relatively light rainfall in the model. This is in line with the common deficiency of current climate models. Perhaps the grid resolution of the climate model simulation used here is insufficient in order to properly resolve the geographic features and various associated climatic phenomena evolving in the subgrid scale. This possibly results in the unrealistic representation of the diurnal rainfall cycle. Indeed, previous studies have suggested that a higher resolution model simulation with a cloud resolving scheme better matches with reality despite the simulated precipitation frequency being still too high compared to observations (Lee et al., 2007; Hohenegger et al., 2008; Sato et al., 2009). We further plan to examine the dependency of the diurnal cycle simulated on the grid resolution of the model by comparing the present results with those from simulations with different spatial resolutions $(25 \mathrm{~km}, 12.5 \mathrm{~km}$ and $6 \mathrm{~km})$. Also, soon there will be some important improvements of physical parametrization of subgridded processes in the next version of RCA model (RCA3.5). We will test the performance of resolving a realistic diurnal cycle of precipitation, which can be an effective metric to check the physical consistency of new parametrization schemes.

The importance of an accurate quantification and simulation of the diurnal precipitation cycle needs to be emphasized again not only for the understanding of the underlying processes and conceptualization of stochastic models (Glasbey et al., 1995; Katz and Parlange, 1995), but also for the practical purposes. Information on the subdaily scale variation of precipitation may be essential for public activities, social planning and water resource management. For instance, the same amount of heavy precipitation could result from either light precipitation being distributed evenly over one day or extreme rainfall pouring a very short period in association with the diurnal cycle, but its meaning is totally different for the infrastructure in society. Despite the deficiencies, future predictions from regional climate models can be very useful information for the long-term planning based on possible alteration of diurnal rainfall characteristics under future climate change conditions. The diurnal variation of precipitation is also important for the weather forecasts. The conventional weather forecasts mostly rely on the synoptic weather system passing by, of which local manifestation can be considerably modulated by the diurnal variation.

\section{Acknowledgments}

Jee-Hoon Jeong was supported by the centre of Earth System Science at University of Gothenburg (TELLUS). The Swedish Research Council (VR), the Gothenburg Atmospheric Science 
Centre (GAC) and FORMAS (grant \#2007-1048-8700*51) are thanked for support to Deliang Chen and Alexander Walther. We thank the data service at SMHI for providing the hourly precipitation measurements being the base for this study. Part of this work has been performed under the Swedish MistraSWECIA programme. Thanks are also due to David Rayner for technical support. We thank the two anonymous reviewers for helpful comments and suggestions.

\section{References}

Andersson, T. 1969. The diurnal variation of precipitation in Sweden. Geografiska Annaler. Series A, Physical Geography. 51, 176-184.

Angelis, C. F. and McGregor, G. R. 2004. Diurnal cycle of rainfall over the Brazilian Amazon. Climate Res. 26, 139-149.

Bakkehoi, S., Oien, K. and Forland, E. J. 1985. An automatic precipitation gauge based on vibrating-wire strain gauges. Nordic Hydrology 16, 193-202.

Brier, G. W. and Simpson, J. 1969. Tropical cloudiness and rainfall related to pressure and tidal variations. Q. J. R. Meteorol. Soc. 95, $120-147$.

Cuxart, J., Bougeault, P. and Redelsperger, J. L. 2000. A turbulence scheme allowing for mesoscale and large-eddy simulations. $Q$. J. $R$. Meteorol. Soc. 126, 1-30.

Dahlström, B. 2006. Regnintensitet i Sverige-en klimatologisk analys (Storm intensities in Sweden - a climatological analysis). VA-Forsk, Nr 2006-26, 1-69.

Dai, A. and Deser, C. 1999. Diurnal and semidiurnal variations in global surface wind and divergence fields. J. Geophys. Res. 104, 31 109-31 125.

Dai, A. and Wang, J. 1999. Diurnal and semidiurnal tides in global surface pressure fields. J. Atmos. Sci. 56, 3874-3891.

Dai, A. 2001. Global precipitation and thunderstorm frequencies, Part II: diurnal variations. J. Clim. 14, 1112-1128.

Dai, A. and Trenberth, K. E. 2004. The diurnal cycle and its depiction in the community climate system model. J. Clim. 17, 930-951.

Dai, A., Lin, X. and Hsu, K.-L. 2007. The frequency, intensity, and diurnal cycle of precipitation in surface and satellite observations over low- and mid-latitudes. Clim. Dyn. 29, 727-744.

Glasbey, C. A., Cooper, G. and McGechan, M. B. 1995. Disaggregation of daily rainfall by conditional simulation from a point-process model. J. Hydrol. 165, 1-9.

Guichard, F., Petch, J. C., Redelsperger, J. L., Bechtold, P., Chaboureau, J. P. and co-authors. 2004. Modelling the diurnal cycle of deep precipitating convection over land with cloud-resolving models and singlecolumn models. Q. J. R. Meteorol. Soc. 130C, 3139-3172.

Hohenegger, C., Brockhaus, P. and Schär, C. 2008. Towards climate simulations at cloud-resolving scales. Meteorol. Z. 17, 383394.

Jones, C. G., Willén, U., Ullerstig, A. and Hansson, U. 2004. The Rossby Centre Regional Atmospheric Climate Model Part I: Model Climatology and Performance for the Present Climate over Europe. Ambio 33, 199-210.

Jones, C. G., Samuelsson, P. and Kjellström, E. 2011. Regional climate modelling at Rossby Centre. Tellus 63A, 1-3.

Kain, J. S. and Fritsch, J. M. 1993. Convective parameterizations for mesoscale models: the Kain-Fritsch scheme. In: The Representation of Cumulus Convection in Numerical Models (eds. Emanuel, K. A. and Raymond, D. J.). American Meteorological Society Monograph, Boston, USA, 246 pp.

Katz, R. W. and Parlange, M. B. 1995. Generalizations of chaindependent processes: application to hourly precipitation. Water Resour. Res. 31, 1331-1341.

Kjellström, E., Bärring, L., Gollvik, S., Hansson, U., Jones, C. and coauthors. 2005. A 140-year simulation of European climate with the new version of the Rossby Centre regional atmospheric climate model (RCA3). In: SMHI Reports Meteorology and Climatology No. 108, $54 \mathrm{pp}$.

Kummerow, C., Barnes, W., Kozu, T., Shiue, J. and Simpson, J. 1998. The tropical rainfall measuring mission (TRMM) sensor package. $J$. Atmos. Ocean. Technol. 15, 809-817.

Lee, M. I., Schubert, S. D., Suarez, M. J., Held, I. M., Kumar, A. and co-authors. 2007. Sensitivity of horizontal resolution in the AGCM simulations of warm season diurnal cycle of precipitation over the United States and Northern Mexico. J. Clim. 20, 18621881.

Lee, M. I., Schubert, S. D., Suarez, M. J., Schemm, J. K. E., Pan, H. L. and co-authors. 2008. Role of convection triggers in the simulation of the diurnal cycle of precipitation over the United States Great Plains in a general circulation model. J. Geophys. Res. D: Atmos., 113, D02111, doi:10.1029/2007JD008984.

Lenderink, G. and van Meijgaard, E. 2008. Increase in hourly precipitation extremes beyond expectations from temperature changes. Nat. Geosci. 1, 511-514.

Nesbitt, S. W. and Zipser, E. J. 2003. The diurnal cycle of rainfall and convective intensity according to three years of TRMM measurements. J. Clim. 16, 1456-1475.

Rasch, P. J. and Kristjansson, J. E. 1998. A comparison of the CCM3 model climate using diagnosed and predicted condensate parameterizations. J. Clim. 11, 1587-1614.

Rio, C., Hourdin, F., Grandpeix, J. Y. and Lafore, J. P. 2009. Shifting the diurnal cycle of parameterized deep convection over land. Geophys. Res. Letters. 36, L07809, doi:10.1029/2008GL036779.

Samuelsson, P., Gollvik, S. and Ullerstig, A. 2006. The landsurface scheme of the Rossby Centre regional atmospheric climate model (RCA3). In: Report in Meteorology 122. SMHI, SE-60176 Norrköping, Sweden, 25 pp.

Samuelsson, P., Jones, C. G., Willén, U., Ullerstig, A., Gollvik, S. and co-authors. 2011. The Rossby Centre Regional Climate model RCA3: model description and performance. Tellus A 63, 4-23.

Sass, B. H., Rontu, L., Savijarvi, H. and Räisänen, P. 1994. HIRLAM-2 Radiation scheme: documentation and tests. In: HIRLAM-2 Radiation Scheme: Documentation and Tests. SMHI, SE-60176 Norrköping, Sweden 43 pp.

Sato, T., Miura, H., Satoh, M., Takayabu, Y. N. and Wang, Y. 2009. Diurnal cycle of precipitation in the tropics simulated in a global cloud-resolving model. J. Clim. 22, 4809-4826.

Savijärvi, H. 1990. Fast radiation parameterization schemes for mesoscale and short-range forecast models. J. Appl. Meteorol. 29, 437-447.

Shin, D. W., Cocke, S. and LaRow, T. E. 2007. Diurnal cycle of precipitation in a climate model. J. Geophys. Res. D: Atmos. 112, D13109 doi:10.1029/2006JD008333. 
Sorooshian, S., Gao, X., Hsu, K., Maddox, R. A., Hong, Y. and coauthors. 2002. Diurnal variability of tropical rainfall retrieved from combined GOES and TRMM satellite information. J. Clim. 15, 983-1001.

Takayabu, Y. N. 2002. Spectral representation of rain profiles and diurnal variations observed with TRMM PR over the equatorial area. Geophys. Res. Lett. 29, 1584, doi:10.1029/2001GL014113.

Undén, P., Rontu, L., Järvinen, H., Lynch, P., Calvo, J. and co-authors. 2002. HIRLAM-5 scientific documentation. In: HIRLAM Report. SMHI, SE-60176 Norrköping, Sweden, 144 pp.

Uppala, S. M., Kallberg, P. W., Simmons, A. J., Andrae, U., Bechtold, V. D. C. and co-authors. 2005. The ERA-40 re-analysis. Q. J. $R$. Meteorol. Soc. 131, 2961-3211.

Wallace, J. M. 1975. Diurnal-Variations in precipitation and thunder- storm frequency over conterminous United States. Mon. Weather Rev. 103, 406-419.

Wern, L. and German, J. 2009. Korttidsnederbörd i Sverige 1995-2008. In: Meteorologi, 139/9002. SMHI.

Wilks, D. S. 2006. Statistical Methods in the Atmospheric Sciences. Academic Press, Burlington, MA.

Woolnough, S. J., Slingo, J. M. and Hoskins, B. J. 2004. The diurnal cycle of convection and atmospheric tides in an aquaplanet GCM. $J$. Atmos. Sci. 61, 2559-2573.

Yin, S., Chen, D. and Xie, Y. 2009. Diurnal variations of precipitation during the warm season over China. Int. J. Climatol. 29, 1154-1170.

Zhang, G. J. 2003. Roles of tropospheric and boundary layer forcing in the diurnal cycle of convection in the U.S. southern great plains. Geophys. Res. Lett. 30, 2281, doi:10.1029/2003GL018554. 